\title{
Parthenolide and DMAPT exert cytotoxic effects on breast cancer stem-like cells by inducing oxidative stress, mitochondrial dysfunction and necrosis
}

\author{
D Carlisi ${ }^{1}$, G Buttitta ${ }^{2}$, R Di Fiore ${ }^{2}$, C Scerri ${ }^{3}$, R Drago-Ferrante ${ }^{2}$, R Vento ${ }^{2,4}$ and G Tesoriere .,1,4 $^{\star 1,}$
}

Triple-negative breast cancers (TNBCs) are aggressive forms of breast carcinoma associated with a high rate of recidivism. In this paper, we report the production of mammospheres from three lines of TNBC cells and demonstrate that both parthenolide (PN) and its soluble analog dimethylaminoparthenolide (DMAPT) suppressed this production and induced cytotoxic effects in breast cancer stem-like cells, derived from dissociation of mammospheres. In particular, the drugs exerted a remarkable inhibitory effect on viability of stem-like cells. Such an effect was suppressed by $\mathrm{N}$-acetylcysteine, suggesting a role of reactive oxygen species (ROS) generation in the cytotoxic effect. Instead z-VAD, a general inhibitor of caspase activity, was ineffective. Analysis of ROS generation, performed using fluorescent probes, showed that both the drugs stimulated in the first hours of treatment a very high production of hydrogen peroxide. This event was, at least in part, a consequence of activation of NADPH oxidases (NOXs), as it was reduced by apocynin and diphenylene iodinium, two inhibitors of NOXs. Moreover, both the drugs caused downregulation of Nrf2 (nuclear factor erythroid 2-related factor 2), which is a critical regulator of the intracellular antioxidant response. Prolonging the treatment with PN or DMAPT we observed between 12 and $24 \mathrm{~h}$ that the levels of both superoxide anion and hROS increased in concomitance with the downregulation of manganese superoxide dismutase and catalase. In addition, during this phase dissipation of mitochondrial membrane potential occurred together with necrosis of stem-like cells. Finally, our results suggested that the effect on ROS generation found in the first hours of treatment was, in part, responsible for the cytotoxic events observed in the successive phase. In conclusion, PN and DMAPT markedly inhibited viability of stem-like cells derived from three lines of TNBCs by inducing ROS generation, mitochondrial dysfunction and cell necrosis.

Cell Death and Disease (2016) 7, e2194; doi:10.1038/cddis.2016.94; published online 14 April 2016

Parthenolide (PN), ${ }^{1-3}$ a sesquiterpene lactone, found in medicinal plants, particularly in feverfew (Tanacetum parthenium), exerts selective toxicity against a wide range of tumors, ${ }^{4-6}$ but is ineffective in normal cells. ${ }^{7}$

Structure of PN exhibits the typical $a$-methylene- $\gamma$-lactone group, which reacts with cysteine thiol groups inducing modifications of many biological functions. The antitumour activity of PN can be mediated by distinct mechanisms: (i) inhibition of NF-KB activity either by inhibition of $I_{\kappa} B$ phosphorylation ${ }^{8}$ or alkylation of $\mathrm{SH}$ groups in the p65 subunit; ${ }^{9}$ (ii) epigenetic mechanism through DNA hypomethylation, determined by downregulation of DNA methyltransferase $1 ;^{10}$ (iii) increment in reactive oxygen species (ROS) generation. In prostate cancer cells, ${ }^{11}$ ROS generation is accompanied by downregulation of antioxidant enzymes, such as manganese superoxide dismutase (MnSOD) and catalase. ${ }^{12}$
Triple-negative breast cancers (TNBCs) are aggressive forms, associated with poor prognosis, ${ }^{13}$ which do not express estrogen, progesterone and Her-2/neu receptors, ${ }^{13}$ and consequently are unresponsive to hormonal treatment. Recently, we showed that PN and dimethylaminoparthenolide (DMAPT), a soluble analog of PN, induced cytotoxic effects in MDA-MB231 cells, ${ }^{14}$ the most studied line of TNBCs, by stimulating ROS generation and autophagy. Moreover, DMAPT decreased tumor growth in mice bearing xenografts of MDA-MB231 cells and induced animal survival. ${ }^{14}$ Finally, suberoylanilide hydroxamic acid, an histone deacetylase inhibitor, synergistically sensitized MDA-MB231 cells to PN effect. $^{15}$

Today a body of evidence strongly suggests that a small proportion of tumor cells, termed cancer stem cells (CSCs), represent the basis for tumor formation, progression,

\footnotetext{
${ }^{1}$ Laboratory of Biochemistry, Department of Experimental Biomedicine and Clinical Neurosciences (BioNec), University of Palermo, Polyclinic, Palermo, Italy; ${ }^{2}$ Laboratory of Biochemistry, Department of Biological, Chemical and Pharmaceutical Sciences and Technologies (STEBICEF), University of Palermo, Polyclinic, Palermo, Italy; ${ }^{3}$ Department of Physiology and Biochemistry, University of Malta, Msida, Malta and ${ }^{4}$ Sbarro Institute for Cancer Research and Molecular Medicine, Center for Biotechnology, Temple University, Philadelphia, PA, USA

*Corresponding author: G Tesoriere, Laboratory of Biochemistry, Polyclinic, via del Vespro 129, Palermo 90127, Italy. Tel: +39 0916552459 ; Fax +39 0916552449 ; E-mail: giovanni.tesoriere@unipa.it

Abbreviations: BAPTA-AM, 1,2-bis-(o-aminophenoxy)-ethane- $N, N, N, N$-tetraacetic acid, tetraacetoxymethyl ester; BCIP, 5-bromo-4-chloro-3-indoyl-phosphate; CSC, cancer stem cell; DETC, diethyldithiocarbamate; DHE, dihydroethidium; DMAPT, dimethylaminoparthenolide; DPI, diphenylene iodinium; $\Delta \psi$ m, mitochondrial membrane potential; FITC, fluorescein isothiocyanate; H2-DCFDA, 5-(and-6)-carboxy-2',7'-dichlorodihydrofluorescein diacetate; HPF, hydroxyphenyl fluorescein; JC-1, 5,5',6,6'tetrachloro-1,1',3,3'-tetraethylbenzimidazolylcarbocyanine iodide; MnSOD, manganese-dependent superoxide dismutase; NAC, N-acetylcysteine; NOX, NADPH oxidase; Nif2, nuclear factor erythroid 2-related factor 2; PDTC, pyrrolidine dithiocarbamate; PI, propidium iodide; PN, parthenolide; ROS, reactive oxygen species; SAHA, suberoylanilide hydroxamic acid; SF, sulforaphane; tBHQ, tert-butylhydroquinone; TNBC, triple-negative breast cancer

Received 04.11.15; revised 01.3.16; accepted 16.3.16; Edited by G Melino
} 
metastasis and recurrence. ${ }^{16-18}$ CSCs have been demonstrated in many tumors including breast cancer. ${ }^{19}$

Interestingly, many drugs, which inhibit replication of the bulk of cancer cells, are not effective for eradication of CSCs in many types of tumors. ${ }^{20-22}$ Consequently, new researches are needed to individuate molecules able to eliminate CSCs.

This paper deals with the production of mammospheres from three distinct lines of TNBCs. Besides, it shows that both PN and DMAPT suppress production of spheres and cause cytotoxic effects in stem-like cells derived from their dissociation.

\section{Results}

PN inhibited production and growth of mammospheres. As Figure 1a shows, PN inhibited viability of three distinct lines of TNBCs, namely MDA-MB231, BT20 and MDAMB436 cells. At $5 \mu \mathrm{M}$, PN reduced viability of the three lines by $25-40 \%$ and at $20 \mu \mathrm{M}$ by $75-80 \%$. Otherwise, $\mathrm{PN}$ at $5 \mu \mathrm{M}$ was ineffective on viability of normal human mammary epithelial cells (HMECs), while at $20 \mu \mathrm{M}$ exerted only a modest effect $(-15 \%)$.

When single cells of the three lines of TNBCs were grown for 10 days in non-adherent conditions, a small number of survival cells generated floating mammospheres, as reported by other authors. ${ }^{23-25}$ Primary mammospheres with at least one diameter $\geqslant 100 \mu \mathrm{m}$ were counted. MDA-MB231 cells were the most active and produced loose and not round mammospheres in the ratio of 5.4/1000 cells. Similar spheres derived from MDA-MB436 cells (1.0/1000 cells), while BT20 cells produced spheres (3.8/1000 cells) with a round conformation. Figure $1 \mathrm{~b}$ shows typical spheres produced from the three lines of cells.

Stem cells are characterized by the expression of some genes required to maintain stem-like conditions. This group includes Nanog, Oct3/4 and Sox2. Figure 1c reports relative mRNA levels ascertained by means of RT-PCR procedure in stem-like cells derived from dissociation of secondary mammospheres produced from the three lines. Nanog exhibited a sharp increase in comparison with parental cells. Also, the levels of Oct3/4 and Sox2 increased, but less than

a

Parental cells

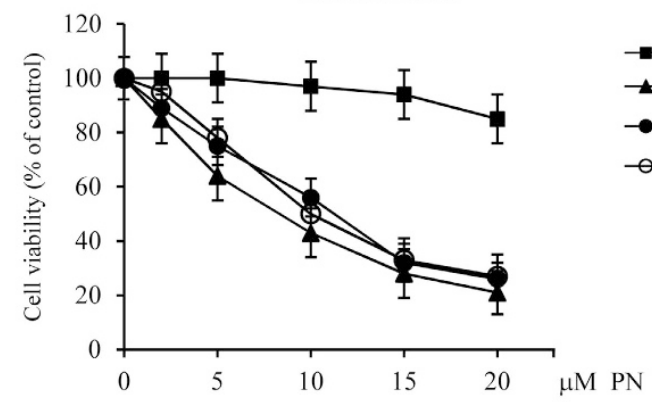

b

Mammospheres
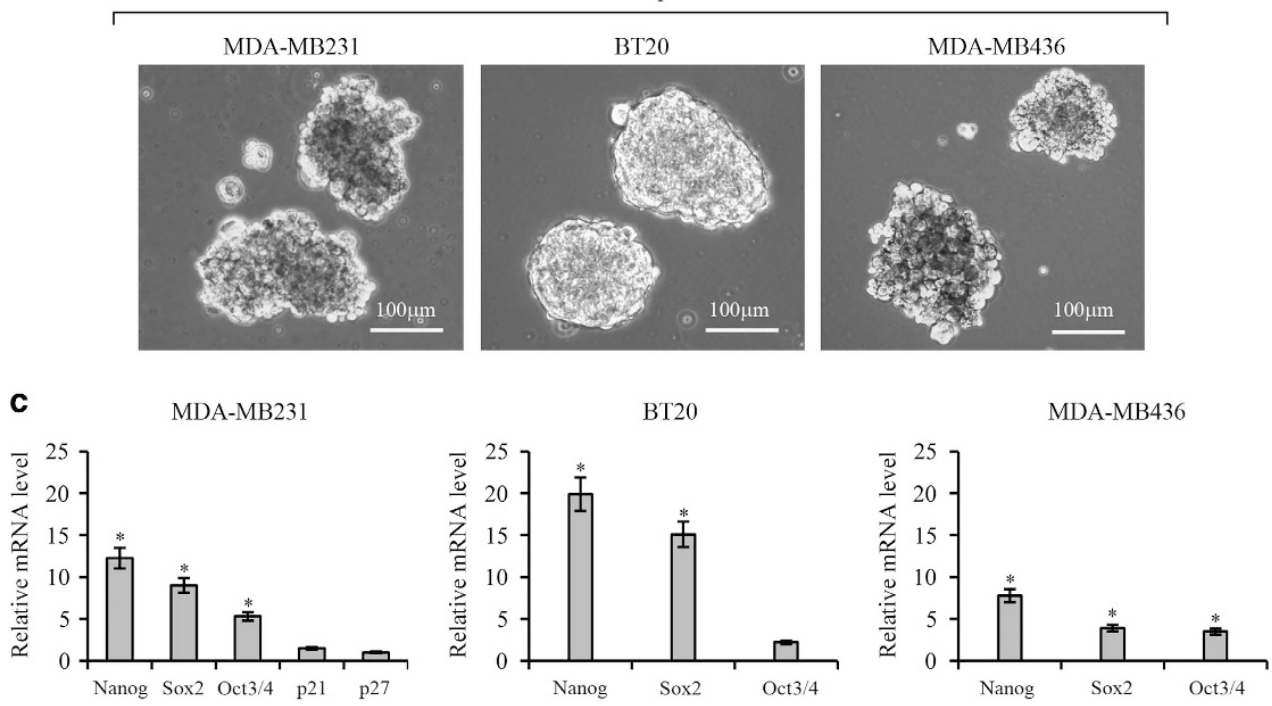

Figure 1 (a) PN inhibits viability of three different lines of TNBC cells. Dose-dependent effect evaluated at $24 \mathrm{~h}$ of treatment of MDA-MB231, BT20 and MDA-MB436 cells with various doses of PN in comparison with HMECs. (b) Images of secondary mammospheres derived from the three lines of TNBC cells under light microscopy at x200 original magnification. (c) Quantitative polymerase chain reaction showing the relative amounts of Nanog, Sox2, Oct3/4, p21 and p27 mRNA in stem-like cells from the three lines. Values reported in the figure express the fold difference in comparison with mRNA measured in the respective parental counterpart. In (b), the results are representative of three independent experiments. Scale bar, $100 \mu \mathrm{m}$. In (a and $\mathbf{c}$ ), the results are the mean of three independent experiments \pm S.D. ${ }^{\star} P<0.01$ versus untreated control 
Nanog, whereas p21 and p27, two oncosuppressor genes, showed only little modifications.

Production of tertiary mammospheres was inhibited by PN or DMAPT in a dose-dependent manner. At $10 \mu \mathrm{M}$ both the compounds suppressed the production of spheres (Figures $2 a$ and b).

In other experiments, various doses of PN were added in non-adherent conditions in the medium containing secondary mammospheres at day 10 of production. PN reduced their number and after 5 days, spheres were almost completely destroyed. Figures $2 \mathrm{c}$ and $\mathrm{d}$ show PN effects on spheres derived from MDA-MB231 cells. Similar results were obtained with spheres derived from the other two lines (not shown).
PN inhibited viability of stem-like cells derived from mammospheres. Stem-like cells derived from dissociation of secondary mammospheres (sphere cells) were used for all the experiments.

Both PN and DMAPT inhibited in a dose-dependent manner the sphere cell viability (Figures $3 a$ and $b$ ). PN exerted a higher effect than DMAPT, in particular at low doses $(2-10 \mu \mathrm{M})$. MDAMB231 sphere cells were the most sensible line.

PDTC (pyrrolidine dithiocarbamate) and DETC (diethyldithiocarbamate), two compounds that like PN inhibit NF- $k \mathrm{~B}$ activity, were unable to inhibit sphere cells viability, except for a modest effect on MDA-MB436 sphere cells (Figures 3a and b). Therefore, viability in stem-like cells is not correlated with NF- $\kappa \mathrm{B}$ activity.

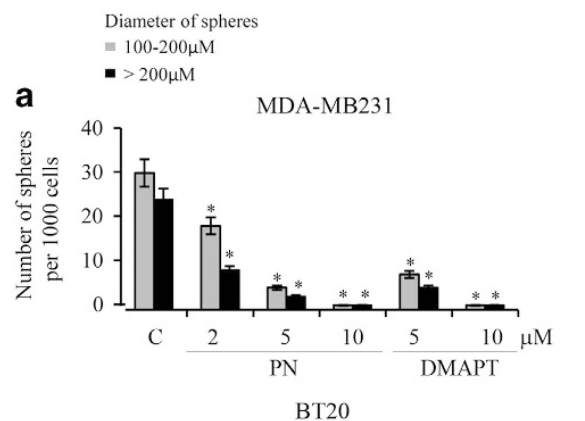

b
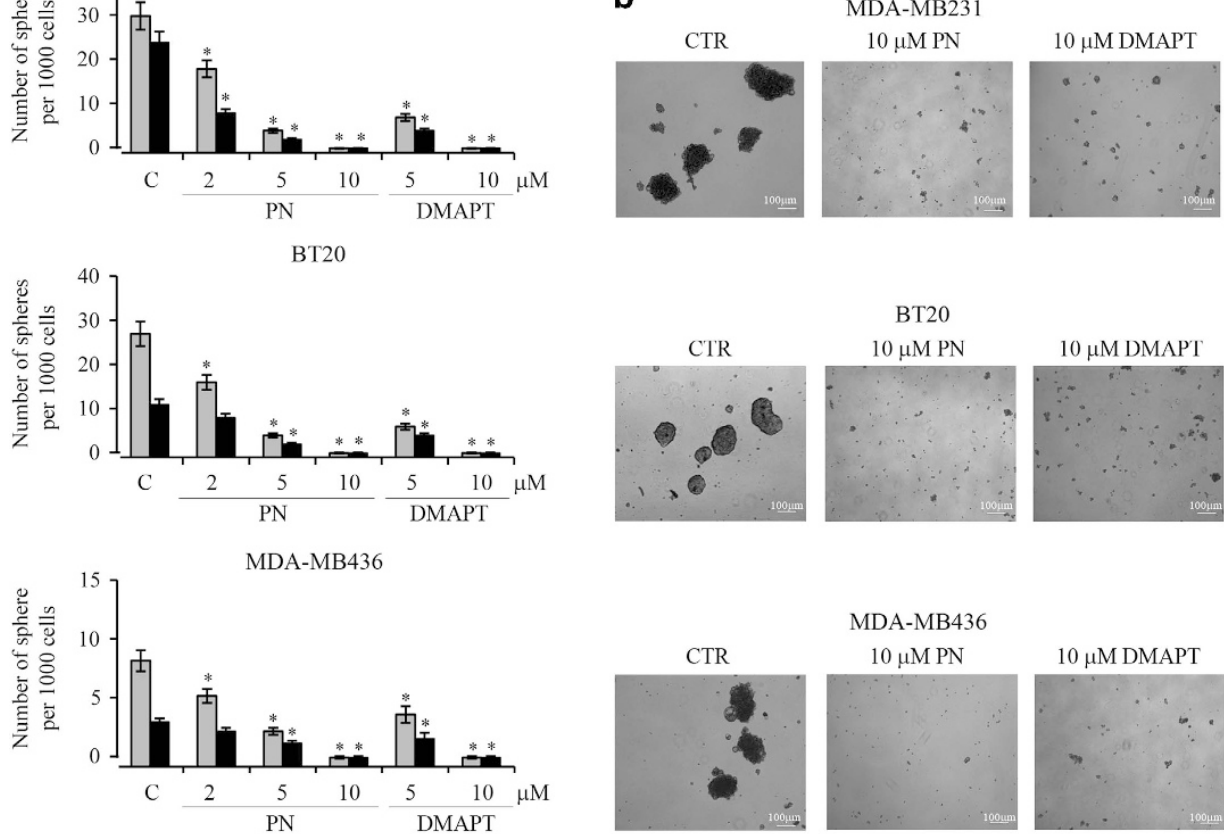

Diameter of spheres

$=100-200 \mu \mathrm{M}$

C

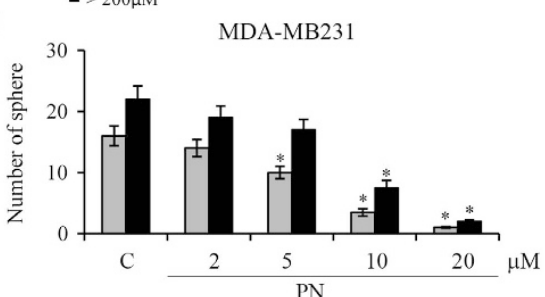

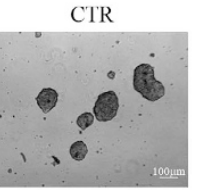

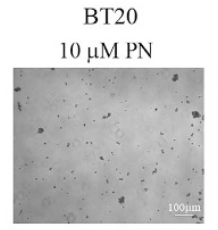

$10 \mu \mathrm{M} \mathrm{DMAPT}$
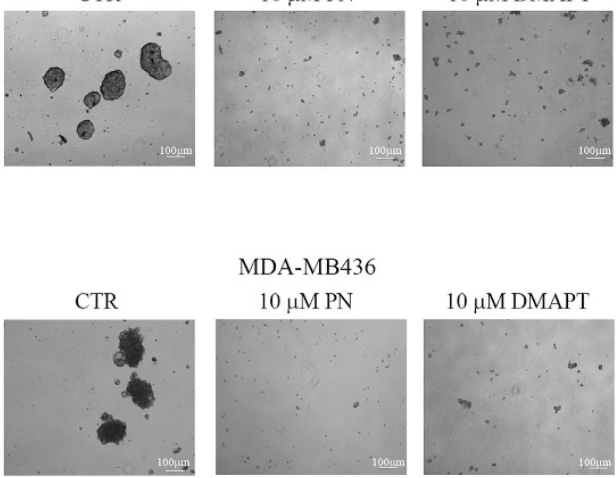

MDA-MB436

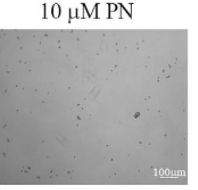

$10 \mu \mathrm{M}$ DMAPT

d

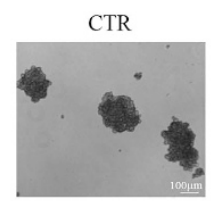

MDA-MB231

$$
10 \mu \mathrm{M} \text { PN }
$$
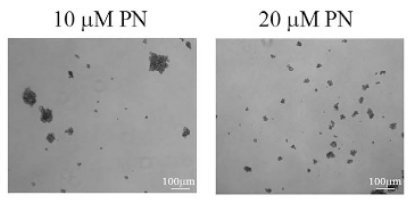

Figure 2 PN and DMAPT inhibited production and stability of mammospheres. (a) PN and DMAPT decreased in a dose-dependent manner the production of secondary mammospheres from the three lines of TNBC cells. Primary mammospheres were dissociated and the isolated cells were again grown for 10 days in non-adherent conditions, as reported in Materials and Methods, without or with PN or DMAPT at various doses. Mammospheres, with at least one diameter $\geqslant 100 \mu \mathrm{m}$ were counted under light microscopy at x100 original magnification. (b) Images showing the effects of $10 \mu \mathrm{M}$ PN and $10 \mu \mathrm{M}$ DMAPT on the production of secondary mammospheres. (c) PN destroyed secondary mammospheres. About 40 secondary mammospheres derived from MDA-MB231 cells at 10 days of growth were treated without or with PN at various doses for other 5 days in non-adherent conditions. (d) Images showing the destructive power exerted by PN on secondary mammospheres derived from MDA-MB231 cells. In (a and c), the results are the mean of three independent experiments \pm S.D. ${ }^{*} P<0.01$ versus untreated control. In ( $\mathbf{b}$ and $\mathbf{d}$ ), the results are representative of three independent experiments. Scale bar, $100 \mu \mathrm{m}$ 
MDA-MB231 sphere cells were more susceptible than parental cells to both PN (Figure 3c) and DMAPT (not shown). Significant differences were observed at 5 and $10 \mu \mathrm{M}$. Instead, differences between sphere and parental cells were not statistically reliable for the two other cell lines.
PN and DMAPT progressively decreased viability of MDAMB231 sphere cells so that at $24 \mathrm{~h}$ of treatment with $10 \mu \mathrm{M} \mathrm{PN}$ viable cells lowered to $\sim 40 \%$ of control (Figures $3 \mathrm{~d}$ and f) and after 6 days (Figure 3e) to only 4\%. A similar behavior was observed using BT20 and MDA-MB436 sphere cells (not shown).

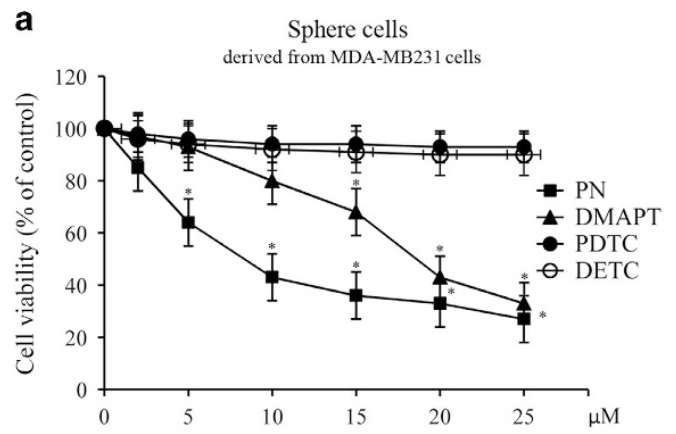

b
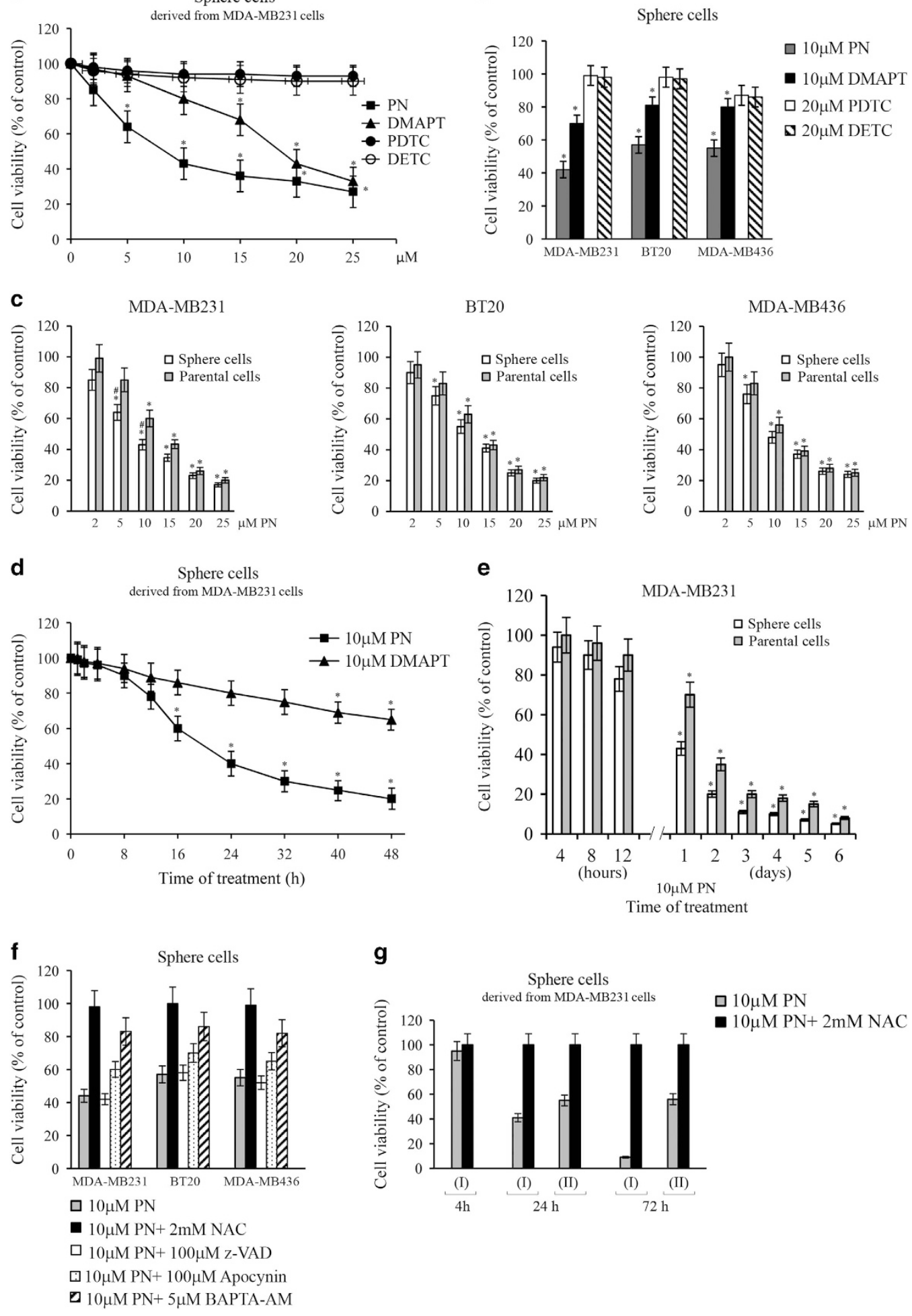
As Figure $3 f$ shows, PN inhibitory effect on cell viability was not modified by z-VAD, a general inhibitor of caspases, but was suppressed by $\mathrm{N}$-acetylcysteine (NAC). Therefore, the effect on cell viability was not a consequence of apoptosis, but of oxidative stress. Moreover, apocynin (100 $\mu \mathrm{M})$, an inhibitor of NADPH oxidase (NOX), ${ }^{26,27}$ and BAPTA-AM (1,2-bis-(o-aminophenoxy)-ethane- $N, N, N^{\prime}, N^{\prime}$-tetraacetic acid, tetraacetoxymethyl ester; $5 \mu \mathrm{M})$, an intracellular $\mathrm{Ca}^{2+}$ chelator, ${ }^{28}$ partially prevented $\mathrm{PN}$ effect, since in their presence PN decreased viability to $60 \%$ and $83 \%$, respectively.

In some experiments, MDA-MB231 sphere cells were at first treated for $4 \mathrm{~h}$ with $10 \mu \mathrm{M} \mathrm{PN}$, then the medium was substituted with fresh medium lacking in $\mathrm{PN}$ and the incubation was started again (condition II). In this case, at $24 \mathrm{~h}$ of incubation sphere cell viability decreased to $56 \%$ of control (Figure $3 \mathrm{~g}$ ). This was a remarkable effect, although minor than that observed in condition I, when PN was maintained continuously for the entire treatment. The inhibitory effect was suppressed in both the conditions by $2 \mathrm{mM}$ NAC. By prolonging the incubation until 3 days, viability further decreased in condition I to a very low level, while in condition II remained at the level found at $24 \mathrm{~h}$.

PN induced ROS generation in stem-like cells. Sphere cells were treated for various times (1-24h) with $10 \mu \mathrm{M}$ $\mathrm{PN}$ and the effects were analyzed using three different fluorescent probes, such as dichlorofluorescein (DCF), dihydroethidium (DHE) and hydroxyphenyl fluorescein (HPF).

Figure $4 \mathrm{a}$ shows the time course of the three signals analyzed in MDA-MB231 sphere cells by fluorescence microscopy. DCFH-DA is a fluorescent probe widely used for $\mathrm{H}_{2} \mathrm{O}_{2}$, but it also reacts strongly with hROS. Ten micromoles of PN rapidly increased the amount of cells positive to DCF signal; at $1 \mathrm{~h}$ of treatment, $\sim 50 \%$ of sphere cells resulted positive to DCF, while with $10 \mu \mathrm{M}$ DMAPT only $25 \%$ were positive (not shown). Then with PN the percentage decreased until $8 \mathrm{~h}$ to only $6 \%$. Afterwards, again increased, reaching at $24 \mathrm{~h}$ the value of $17 \%$.

Figure $4 \mathrm{~b}$ reports images of fluorescence microscopy showing that PN effect at $1 \mathrm{~h}$ of treatment was suppressed by $2 \mathrm{mM}$ NAC and markedly reduced by apocynin and DPI, two inhibitors of NOX, and by BAPTA-AM. Interestingly, $5 \mu \mathrm{M}$ sulforaphane (SF) ${ }^{29}$ and $25 \mu \mathrm{M}$ tert-butylhydroquinone (tBHQ), ${ }^{30}$ two activators of Nrf2, suppressed PN effect on DCF signal. Histograms, reported in the inset of Figure $4 \mathrm{~b}$, indicate the percentages of fluorescent-positive cells estimated in the various conditions. The results were confirmed by cytofluorimetric analysis shown in Figure 4c.

Superoxide radical was detected by using the fluorochrome DHE (Figure 4a). DHE-positive cells were not observed in the first $8 \mathrm{~h}$. Afterwards, their number progressively increased, reaching at $24 \mathrm{~h}$ the percentage of $\sim 27 \%$ of the total cell number.

hROS were detected by using the fluorescent probe HPF (Figure 4a). Also in this case positivity to HPF, proving production of hydroxyl radicals and peroxynitrite, was observed after the first $8 \mathrm{~h}$ of treatment.

Finally, $10 \mu \mathrm{M}$ PN strongly induced ROS generation also in BT20 sphere cells, while a minor effect was ascertained in MDA-MB436 sphere cells (Figure 4d).

In parental cells, as observed previously, ${ }^{31} \mathrm{PN}$ stimulated ROS generation but at higher concentration (15-25 $\mu \mathrm{M})$, while $10 \mu \mathrm{M}$ was ineffective.

PN downregulated Nrf2 in sphere cells. We investigated about the effect of both PN and DMAPT on the expression of Nrf2, a critical regulator of the intracellular antioxidant response. $^{32,33}$ Western blotting analysis demonstrated that treatment of MDA-MB231 sphere cells for $2 \mathrm{~h}$ with $10 \mu \mathrm{M}$ PN decreased Nrf2 expression by $40 \%$ (Figure $5 \mathrm{a}$ ). Then, the level increased with the time of incubation, reaching at $24 \mathrm{~h}$ a value near to the control. A minor effect on Nrf2 expression was exerted by DMAPT (Figure 5b). PN effect was much higher in sphere cells compared with that in the parental counterpart, where PN treatment for $2 \mathrm{~h}$ decreased Nrf2 level by only $15 \%$. Five micromoles of SF or $25 \mu \mathrm{M}$ tBHQ, two activators of Nrf2, increased in sphere cells the basal level of Nrf2 (Figure 5c). Furthermore, both SF and tBHQ suppressed Nrf2 downregulation induced by PN. The effect on Nrf2 was dose-dependent (Figure $5 \mathrm{~d}$ ). At $2 \mathrm{~h}$ of treatment, a clear decrease in the intensity of Nrf2 band was observed already with $5 \mu \mathrm{M} \mathrm{PN}$; then, the effect increased with $\mathrm{PN}$ dose, reaching the maximum with $15 \mu \mathrm{M}$. As 2 mM NAC (Figure 5e) did not modify PN effect, downregulation of Nrf2 was not a consequence of oxidative stress.

PN decreased Nrf2 level also in BT20 sphere cells (Figure 5f) with a similar effect to that observed in MDAMB231 sphere cells.

PN induced in sphere cells dissipation of mitochondrial membrane potential and caused cell necrosis. As PN inhibited sphere cell viability in particular between 8 and $24 \mathrm{~h}$ of treatment, we investigated about the events occurring

Figure 3 PN and DMAPT inhibited viability of mammosphere-derived cells. Secondary mammospheres, derived from three lines of TNBCs, were dissociated to produce isolated sphere cells, which were plated $\left(8 \times 10^{3} /\right.$ well) in adherent conditions. After $24 \mathrm{~h}$, sphere cells were used for the experiments. At the end, viability was evaluated by MTT assay. (a) Dose-dependent effect evaluated at $24 \mathrm{~h}$ of treatment with various doses of PN or DMAPT in comparison with PDTC and DETC in MDA-MB231 sphere cells. (b) Comparison of the effects determined by $24 \mathrm{~h}$ treatment with PN, DMAPT, PDTC and DETC in sphere cells derived from the three lines of TNBCs. (c) Dose-dependent effect induced by $24 \mathrm{~h}$ of treatment with PN. Comparison between sphere cells and the respective parental cells. (d) Time course of the effects exerted by PN and DMAPT on MDAMB231 sphere cells. (e) Comparison between the time-dependent effect exerted by $10 \mu \mathrm{M}$ PN on MDA-MB231 sphere cells and the respective parental cells. (f) The inhibitory influence exerted by various compounds on the effect induced by treatment for $24 \mathrm{~h}$ with $10 \mu \mathrm{M}$ PN in sphere cells derived from the three lines of TNBCs. (g) The effect of substitution of the medium in MDA-MB231 sphere cells treated with PN. (I) Control condition. Sphere cells were treated continuously with PN or PN plus NAC during the incubation. Viability was evaluated at 4, 24 and $72 \mathrm{~h}$ of treatment. (II) Sphere cells were treated for $4 \mathrm{~h}$ with PN or PN plus NAC, then the medium was substituted with fresh medium lacking in both PN and NAC and the incubation was continued. Viability was evaluated at 24 and $72 \mathrm{~h}$ of treatment. All the data shown in this figure are the mean of three independent experiments \pm S.D. ${ }^{*} P<0.01$ versus untreated control; ${ }^{*} P<0.01$ versus parental cells 
during this phase. At first we studied, using the fluorescent cationic dye JC-1 (5,5',6,6'-tetrachloro-1,1',3,3'-tetraethylbenzimidazolylcarbocyanine iodide), whether the exposure to PN modified mitochondrial membrane potential $(\Delta \psi \mathrm{m})$.
When MDA-MB231 sphere cells were incubated without $\mathrm{PN}$, red-orange fluorescence prevailed on greenish fluorescence, suggesting that most of the cells were polarized. Greenish fluorescence markedly increased after treatment with $10 \mu \mathrm{M} \mathrm{PN}$, indicating dissipation of $\Delta \psi \mathrm{m}$. The effect

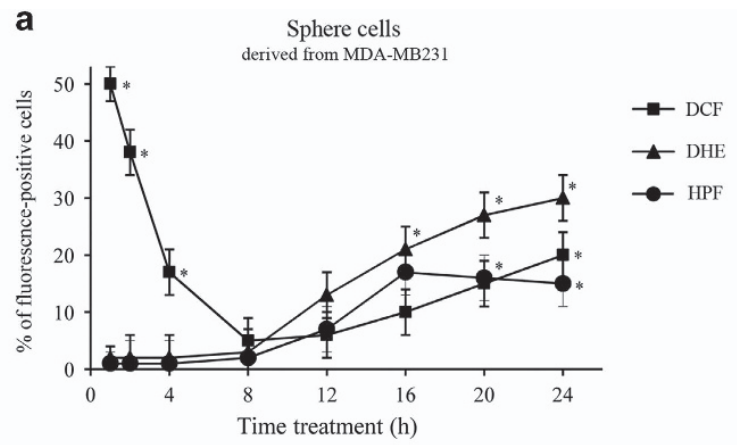

b Sphere cells derived from MDA-MB231

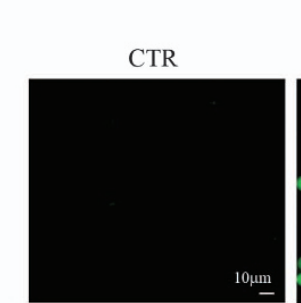

$10 \mu \mathrm{M}$ PN+ $5 \mu \mathrm{M}$ DPI

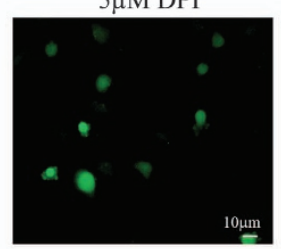

C

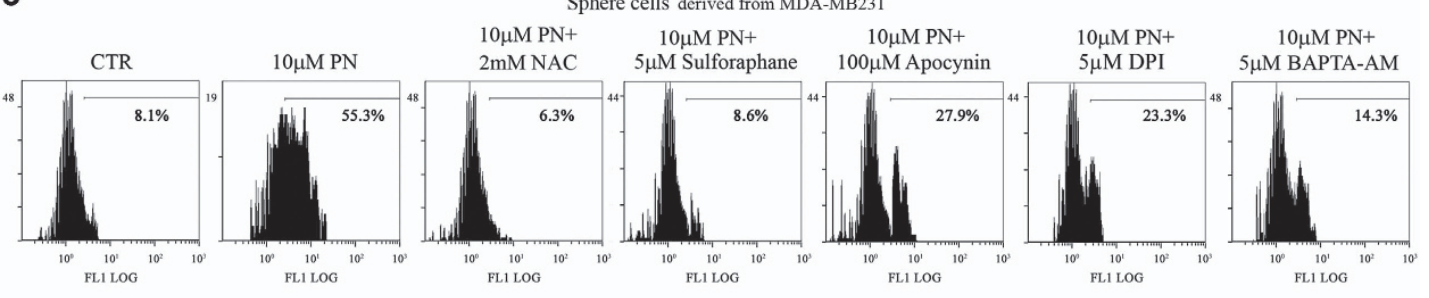

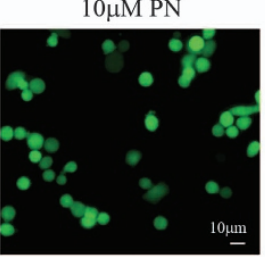

$10 \mu \mathrm{M} \mathrm{PN}+$ $5 \mu \mathrm{M}$ BAPTA-AM

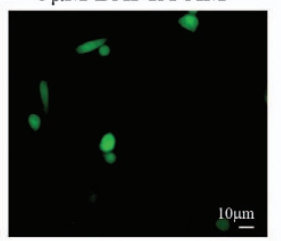

$10 \mu \mathrm{M}$ PN + $5 \mu \mathrm{M}$ Sulforaphane

$10 \mu \mathrm{M} \mathrm{PN}+$
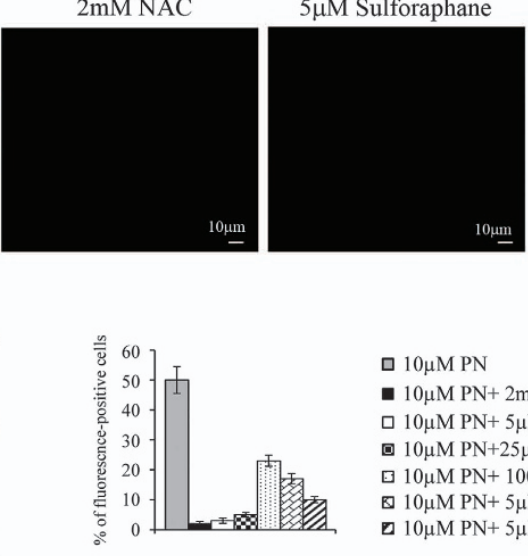

口 $10 \mu \mathrm{M}$ PN

- $10 \mu \mathrm{M} \mathrm{PN}+2 \mathrm{mM}$ NAC

$\square 10 \mu \mathrm{M}$ PN $+5 \mu \mathrm{M}$ Sulforaphane

口 $10 \mu \mathrm{M} \mathrm{PN}+25 \mu \mathrm{M} \mathrm{t}-\mathrm{BHQ}$

口 $10 \mu \mathrm{M} \mathrm{PN}+100 \mu \mathrm{M}$ Apocynin

$\checkmark 10 \mu \mathrm{M} \mathrm{PN}+5 \mu \mathrm{M}$ DPI

च $10 \mu \mathrm{M}$ PN $+5 \mu \mathrm{M}$ BAPTA-AM
$10 \mu \mathrm{M} \mathrm{PN}+$

$100 \mu \mathrm{M}$ Apocynin

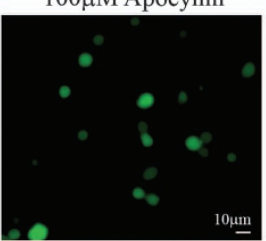

d Sphere cells

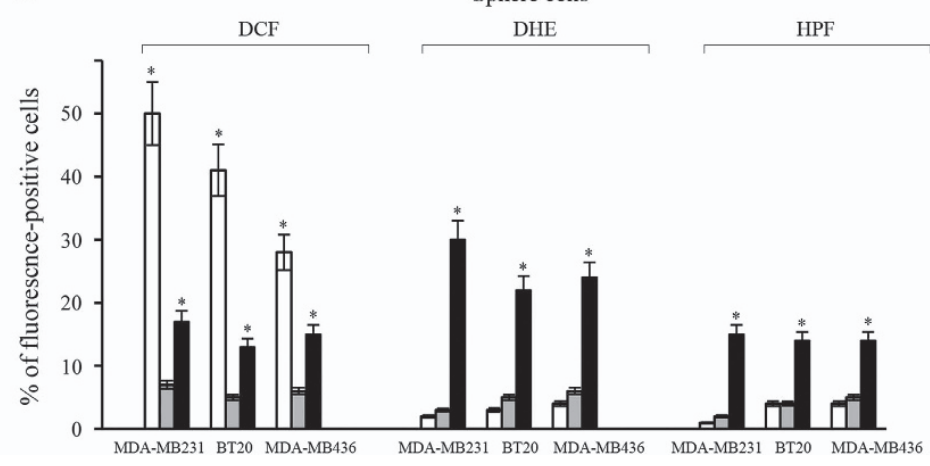


already appeared at $12 \mathrm{~h}$ and reached the maximum at $24 \mathrm{~h}$, when most of the cells were depolarized. Two micromoles of NAC suppressed $\Delta \psi \mathrm{m}$ dissipation induced by PN. Figure $6 \mathrm{a}$ (conditions I, II and III) shows merged images relative to sphere cells, treated for $24 \mathrm{~h}$ with PN. In condition IV, the medium containing PN was substituted after $4 \mathrm{~h}$ of treatment with fresh medium lacking in PN and the incubation was continued. Also in this case greenish fluorescence clearly prevailed in merged images at $24 \mathrm{~h}$ of incubation, but the efficacy of the treatment was minor. PN induced dissipation of $\Delta \psi \mathrm{m}$ also in sphere cells derived from the two other lines of TNBCs (Figure 6b), but with a lower efficacy in comparison with MDA-MB231 sphere cells.

In agreement with previous observations reported for prostate cancer cells, ${ }^{12} 10 \mu \mathrm{M}$ PN decreased in MDAMB231 sphere cells both MnSOD and catalase levels (Figure 6c). The effects appeared at $8 \mathrm{~h}$ of treatment and reached the maximum at $24 \mathrm{~h}$, in concomitance with the increment in the levels of superoxide anion and hROS.

To study the time course of the cytotoxic effect induced by $\mathrm{PN}$, sphere cells were treated with propidium iodide $(\mathrm{PI})$. The amount of $\mathrm{PI}$-positive cells increased very slowly in the first $8 \mathrm{~h}$ of treatment with $10 \mu \mathrm{M} \mathrm{PN}$, then more rapidly, in accordance with $\mathrm{PN}$ effect exerted on cell viability, reaching for MDA-MB231 sphere cells at $24 \mathrm{~h}$ the proportion of $80 \%$ of the total cells (Figure 6d), while for BT20 and MDA-MB436 sphere cells, PI-positive cells reached $70 \%$ and $65 \%$, respectively.

Interestingly, when the medium containing PN was substituted after $4 \mathrm{~h}$ of treatment with medium lacking in PN, changes in MnSOD and catalase levels were not observed in MDA-MB231 sphere cells at $24 \mathrm{~h}$ of treatment. Moreover, in this case the amount of $\mathrm{PI}$-positive sphere cells reached at $24 \mathrm{~h}$ only the proportion of $33 \%$ (not shown).

To ascertain the mechanism of cytotoxic effect, sphere cells were stained with Annexin V-FITC (fluorescein isothiocyanate)/PI and analyzed by flow cytometry at various times of treatment with $10 \mu \mathrm{M}$ PN. Using MDA-MB231 sphere cells, population of positive cells to both Annexin V and PI (C2) increased during treatment, reaching at $24 \mathrm{~h}$ the percentage of $43.1 \%$ (Figure 6e). Although these cells could be either late apoptotic or necrotic dead cells, we concluded that they are necrotic dead cells, as modest amounts of early apoptotic cells (C4) were found during the treatment, and at $24 \mathrm{~h}$ cells in $\mathrm{C} 4$ accounted for $3.6 \%$, a value inferior than that found in the control (4.4\%). Instead, cells undergoing necrosis (C1) exhibited a different trend and at $24 \mathrm{~h}$ their amount increased from $1.0 \%$ of control to $5.3 \%$ of treated cells. PN effect was completely abolished by $2 \mathrm{mM}$ NAC. Similar results were obtained using BT20 and MDA-MB436 sphere cells. In particular, cells in $\mathrm{C} 2$ reached at $24 \mathrm{~h}$ of treatment the percentages of $40.2 \%$ and $38.6 \%$, respectively.

\section{Discussion}

Regenerative ability of tumors depends on a small population of self-renewing CSCs. ${ }^{17,34}$ Proliferation of normal stem cells is submitted to a control leading to the production of various typologies of cells. CSCs are lacking in this control and in the active state induce a progressive increase in undifferentiated cells causing the generation of tumors. Besides, CSCs exhibit many protective systems, ${ }^{35}$ consisting in multifunctional efflux transporters and in mechanisms directed against apoptosis. Therefore, CSCs display clinical resistance to chemotherapeutic agents and to radiation and after conventional treatment can remain vital, although in a silent state. However, CSCs can be activated by the surrounding microenvironment, ${ }^{36,37}$ leading to recurrence or distant metastasis. Consequently, new approaches to kill CSCs and to eliminate cancer recurrence represent a new possible strategy against tumors.

PN was identified in leukemia and in solid tumors as the first small molecule capable of killing CSCs. ${ }^{38}$ Recently, Zhou et al. ${ }^{24}$ showed that PN inhibited the production of mammospheres from breast cancer MCF-7 cells, an effect that was caused by inhibition of NF- $\kappa$ B activity.

TNBCs often exhibit acquired resistance when submitted to standard chemotherapy ${ }^{39}$ and undergo recurrence and metastasis. As these events depend on stem cell activity, we investigated in this research about the effects exerted by PN and DMAPT on stem-like cells. We ascertained that both PN and DMAPT suppressed the production of mammospheres from the three lines of cells. Besides, the two compounds inhibited viability of stem-like cells prepared from mammospheres. This inhibitory effect was clearly evident for MDAMB231 sphere cells at low doses $(2-10 \mu \mathrm{M})$ of PN.

To clarify the mechanism of these effects, we investigated about the role of PN in ROS generation, as suggested by two considerations: (i) intracellular ROS level, which is essential in cell viability control, results from the balance between the mechanisms that produce ROS and the antioxidant activities. In cancer cells, discrete amounts of ROS are involved in the stimulation of prosurvival pathways, ${ }^{40,41}$ but increment in ROS level causes structural damages and activation of antisurvival pathways. (ii) Previously, we showed ${ }^{14}$ that the cytotoxic effect

Figure $4 \mathrm{PN}$ induced generation of oxygen radicals in sphere cells derived from three lines of TNBCs. Sphere cells $\left(8 \times 10^{3}\right.$ cells per well) were treated for various times (1-24 h) with $10 \mu \mathrm{M} \mathrm{PN}$. Three different fluorescent probes were used: DCF, DHE and HPF. Fluorescent cells were visualized with a Leica DC $300 \mathrm{~F}$ microscope at x200 original magnification with fluorescent filters for FITC (DCF and HPF) or rhodamine (DHE). Cells with fluorescence were counted in three different microscopic fields in each well ( 3 wells per treatment) and expressed as percentage of the total number of cells counted under light microscopy. (a) The time course of DCF, DHE and HPF signals analyzed by fluorescence microscopy in MDA-MB231 sphere cells treated with $10 \mu \mathrm{M}$ PN. (b) Images of fluorescence microscopy showing the inhibitory influence exerted in MDA-MB231 sphere cells by various compounds on the effect induced on DCF signal by treatment for $1 \mathrm{~h}$ with $10 \mu \mathrm{M}$ PN. In the inset, histograms showing the percentage of fluorescencepositive cells observed in the various conditions. (c) Flow cytometric detection of DCF signal in the same conditions shown in (b). (d) The effect of $10 \mu \mathrm{M}$ PN on the amount of positive cells to DCF, DHE and HPF signals analyzed by fluorescence microscopy for various times in sphere cells derived from the three lines of TNBCs. In (a, $\mathbf{b}$, inset and $\mathbf{d})$ ), the results are the mean of three independent experiments \pm S.D. ${ }^{*} P<0.01$ versus untreated control. In $(\mathbf{b}$, images and $\mathbf{c})$, the results are representative of three independent experiments. Scale bar, $10 \mu \mathrm{m}$ 
a

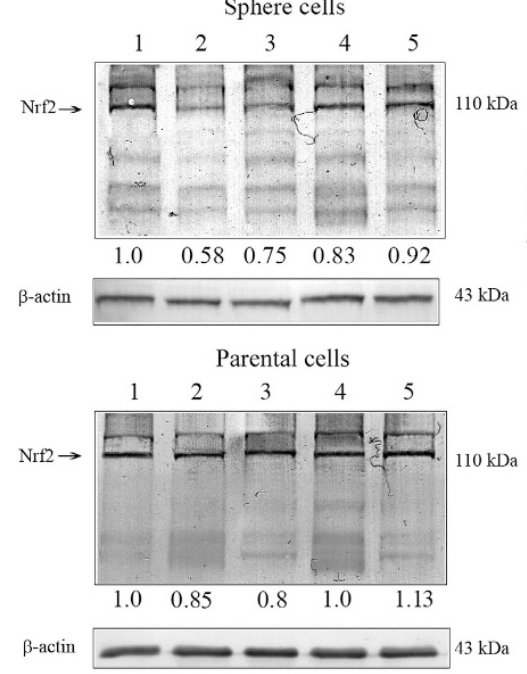

b

MDA-MB23

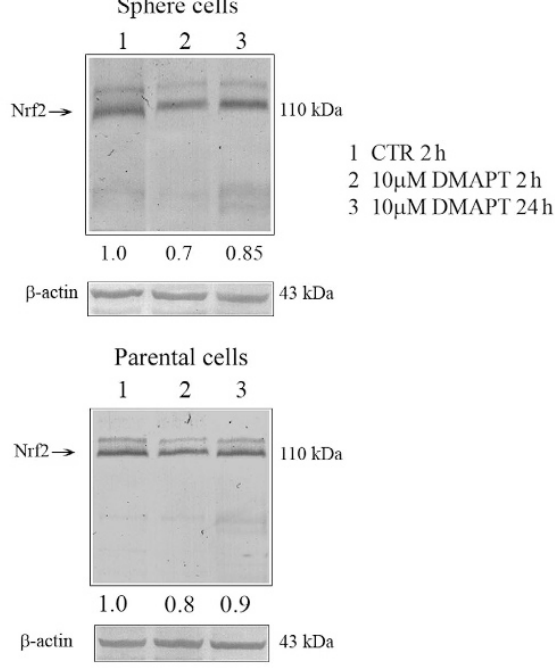

c

1. CTR

2. $10 \mu \mathrm{M}$ PN $2 \mathrm{~h}$

3. $10 \mu \mathrm{M}$ PN $4 \mathrm{~h}$

4. $10 \mu \mathrm{M}$ PN $8 \mathrm{~h}$

5. $10 \mu \mathrm{M}$ PN $24 \mathrm{~h}$

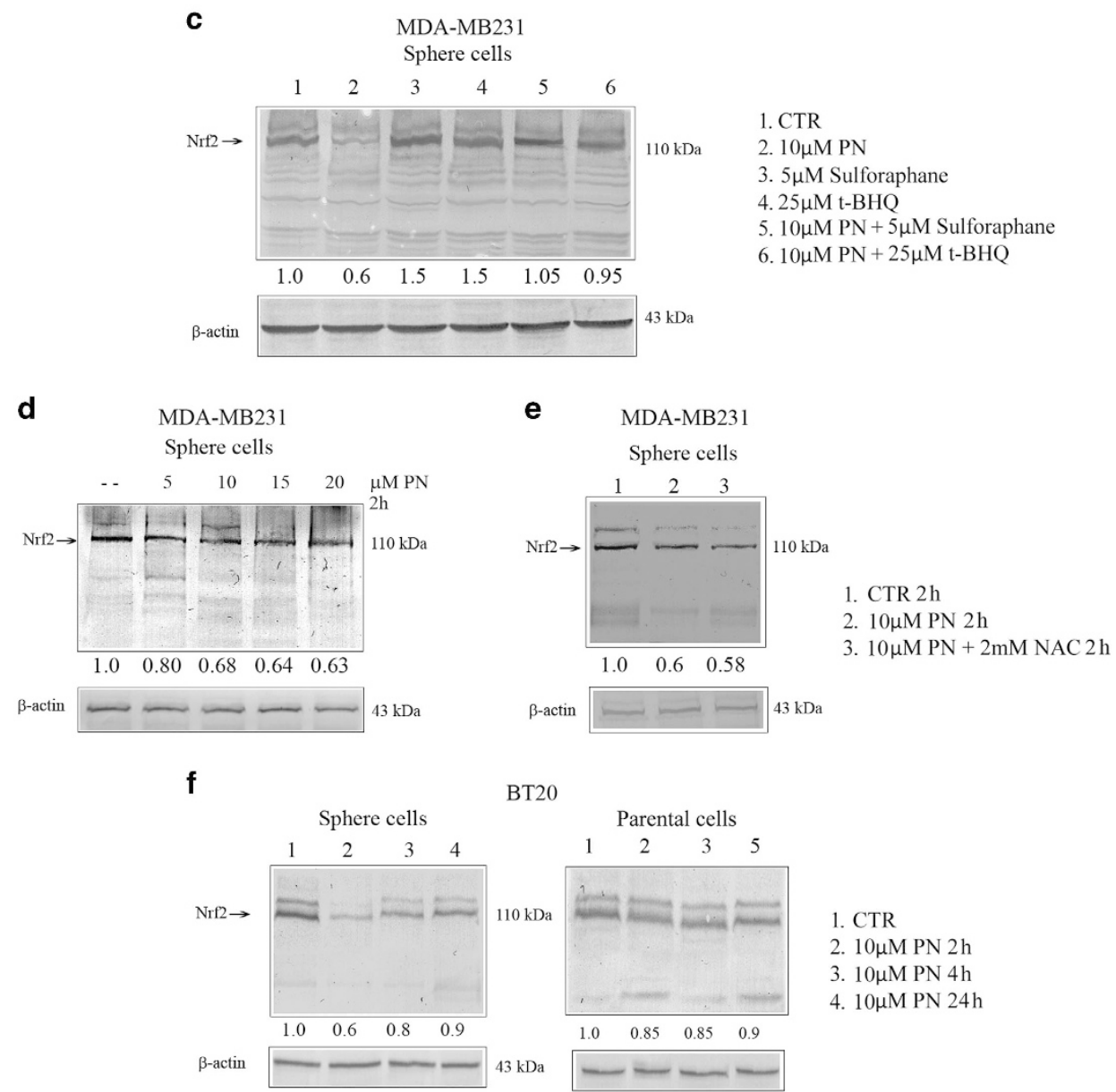

Figure 5 Western blotting analysis showing the effects of PN and DMAPT on the expression of Nrf2. Ten micromoles of PN (a) and $10 \mu \mathrm{M}$ DMAPT (b) caused downregulation of Nrf2 expression in MDA-MB231 sphere cells. Time dependence of the effect in comparison with the parental cells. (c) SF and tBHQ suppress downregulation of Nrf2 induced by PN in MDA-MB231 sphere cells. Sphere cells were previously incubated for $2 \mathrm{~h}$ without or with the activators of Nrf2, SF or tBHQ. Then, $10 \mu \mathrm{M}$ PN was added and the treatment was protracted for other $2 \mathrm{~h}$. (d) The dose dependence of PN effect in MDA-MB231 sphere cells. (e) The addition of 2 mM NAC did not modify PN effect observed at $2 \mathrm{~h}$ of treatment. (f) The time dependence of PN effect in BT20 sphere cells in comparison with the parental cells. All the results are representative of three independent experiments 
exerted by PN in MDA-MB231 cells is correlated with ROS generation.

Interestingly, ROS level in breast CSCs is lower compared with that in non-stem counterparts. ${ }^{42,43}$ Moreover, it seems that the intracellular amount of ROS must remain at low levels to assure stem cell viability. Consequently, the increase in ROS level could represent an effective mechanism for the induction of CSC death.

Our results show that DCF-positive sphere cells markedly enhanced at $1 \mathrm{~h}$ of PN treatment with PN. DCF signal is induced not only by $\mathrm{H}_{2} \mathrm{O}_{2}$ but also by hROS. As the specific probe HPF showed that in the first hours of treatment hROS were not detected, it seems that the positivity to DCF signal was entirely due to $\mathrm{H}_{2} \mathrm{O}_{2}$ production. Furthermore, as DCFpositive cells were markedly decreased by both apocynin and DPI, two effective inhibitors of various forms of NOXs, we suggest that NOXs have a role in ROS generation in the first hours of treatment, although other mechanisms can be involved in this process. Finally, also BAPTA-AM markedly reduced positivity to DCF signal. Therefore, $\mathrm{PN}$ could induce NOX activation through a $\mathrm{Ca}^{2+}$-dependent mechanism. In this regard, it was demonstrated that $\mathrm{Ca}^{2+}$ regulates activation and translocation of Rac, ${ }^{44}$ a component of NOX complex, and that elevation of intracellular $\mathrm{Ca}^{2+}$ stimulates NOX5 to generate superoxide. ${ }^{45}$

To ascertain whether the increase in $\mathrm{H}_{2} \mathrm{O}_{2}$ level can also result from a decrease in the antioxidant activities, we investigated about the effect of PN on Nrf2 expression. The transcription factor Nrf2 controls the expression of many antioxidant and detoxifying genes. ${ }^{32,33}$ Nrf2 is regulated by Keap $1,{ }^{46-48}$ a factor that mediates ubiquitination and the consequent proteasomal degradation of Nrf2. Recently, it has been shown that brusatol, an inhibitor of Nrf2 pathway, markedly decreases the Nrf2 level, ${ }^{49,50}$ while it enhances intracellular ROS and sensitizes tumor cells to chemotherapeutic drugs. These results demonstrate that Nrf2 exerts an important role in the control of the antioxidant response.

This paper shows that PN downregulates Nrf2 expression in sphere cells, an effect suppressed by both SF and tBHQ, two activators of Nrf2. Downregulation of Nrf2, which was observed after a brief period of treatment with PN, could be, at least partially, responsible for the rapid induction of ROS level caused by PN. This conclusion is supported by the observation that both $\mathrm{SF}$ and $\mathrm{tBHQ}$ markedly reduced $\mathrm{PN}$ effect on DCF signal.

In conclusion, we show that $10 \mu \mathrm{M}$ PN and DMAPT increased in stem-like cells the $\mathrm{H}_{2} \mathrm{O}_{2}$ level in the first hours of treatment, whereas at this dose they were ineffective on the parental counterparts. Although it seems clear that NOX activation and Nrf2 downregulation are implicated in PN activity, however, the exact mechanisms by which the drugs increased ROS level in stem-like cells are unclear at the moment. Therefore, these aspects deserve new investigations. With regard to PN effect on the Nrf2 level, we hypothesize that PN can act similarly to brusatol, ${ }^{51}$ which reduces the Nrf2 level through enhanced ubiquitination and degradation of Nrf2 protein.

In the second phase of treatment (12-24 h), dysfunction of mitochondrial activity occurred, as suggested by dissipation of
$\Delta \psi \mathrm{m}$, which increased from $12 \mathrm{~h}$ to $24 \mathrm{~h}$, when most of the cells were depolarized. In this regard, the role of ROS is suggested by the suppression of mitochondrial depolarization determined by NAC. Mitochondrial dysfunction can depend on intracellular thiol depletion, caused by ROS generation in the first hours of treatment. Moreover, in the second phase of treatment mitochondrial dysfunction, together with the decrement in MnSOD and catalase levels, can indeed stimulate the production of radical species (superoxide anion and hROS), and these can further increase the mitochondrial dysfunction and cytotoxic effects. A relationship between ROS generation and thiol depletion was previously demonstrated by us in TNBC cells. ${ }^{14}$

During the second phase of treatment in concomitance with mitochondrial depolarization, viability of sphere cells exhibited a progressive decrement. Accordingly, the amount of PIpositive cells progressively increased. However, PN and DMAPT did not stimulate apoptotic events, as their effect on cell viability was not prevented by z-VAD. Moreover, Annexin $\mathrm{V} / \mathrm{PI}$ test showed that the drugs caused a progressive increment in necrotic cells between 12 and $24 \mathrm{~h}$. In conclusion, PN and DMAPT also at low doses induced the generation of radical species and mitochondrial depolarization with the consequent cell necrosis.

It seems that $\mathrm{H}_{2} \mathrm{O}_{2}$ generated in the first hours of treatment was partially responsible for the cytotoxicity observed in the successive phase. In fact, when the cells were treated with PN only for the first $4 \mathrm{~h}$ and then the drug was removed, a partial decrement in cell viability and a partial depolarization of sphere cells were observed. However, the persistent presence of PN also in the second phase was a decisive to induce downregulation of MnSOD and catalase, as well as to increase depolarization of sphere cells and cell necrosis.

Chemotherapy with platinum agents, anthracyclines and taxanes represents today the elective treatment for TNBCs. ${ }^{38}$ As this therapy is accompanied by a high rate of recidivism, a novel treatment strategy is urgently needed. ${ }^{52,53}$ Our results, concerning the effects exerted by PN and DMAPTon stem-like cells derived from TNBCs, strongly suggest that the two drugs can be used for new therapeutic strategies against TNBCs. Moreover, association with other drugs could be useful to increase oxidative stress and cytotoxic effect induced by PN. Finally, it seems possible that PN, increasing ROS level, can sensitize breast CSCs to radiation, as previously ascertained in prostate cancer cells. ${ }^{12,54}$ This consideration suggests a combination of PN treatment with irradiation to improve the effectiveness of therapy for TNBCs.

\section{Materials and Methods}

Chemicals and reagents. PN was supplied by Sigma-Aldrich (Milan, Italy), whereas DMAPT was supplied by Biomol (Plymouth Meeting, PA, USA). All the other reagents were purchased from Sigma-Aldrich, except for Z-Vad-fmk, which was supplied by Promega (Milan, Italy).

Cell cultures. HMECs were purchased from Lonza (Walkersville, MD, USA) and grown according to the manufacturer's instructions. Three different lines of TNBC cells, supplied by 'Istituto Scientifico Tumori' (Genoa, Italy), were used for these experiments. MDA-MB231 cells were grown as a monolayer in Dulbecco's modified Eagle's medium (DMEM), BT20 cells in minimum essential medium (MEM) and MDA-MB436 cells in Roswell Park Memorial Institute (RPMI-1640). The three media were supplemented with $10 \%$ fetal calf serum, $2 \mathrm{mM}$ glutamine, $1 \%$ non-essential 


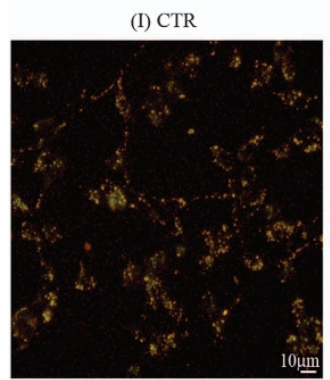

b
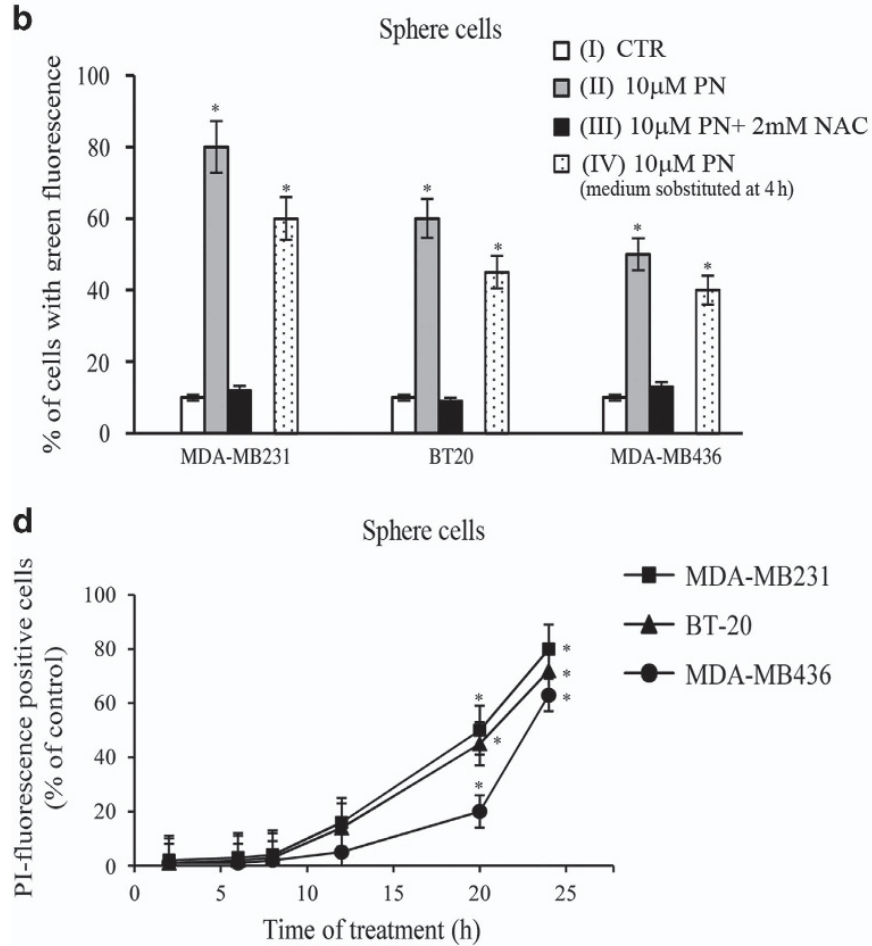

Sphere cells

derived from MDA-MB231 cells

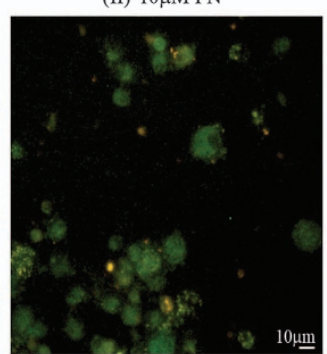

(IV) $10 \mu \mathrm{M}$ PN

(medium sobstituted at $4 \mathrm{~h}$ )

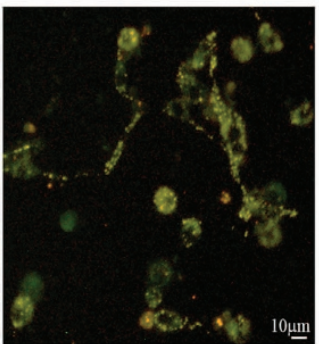

C
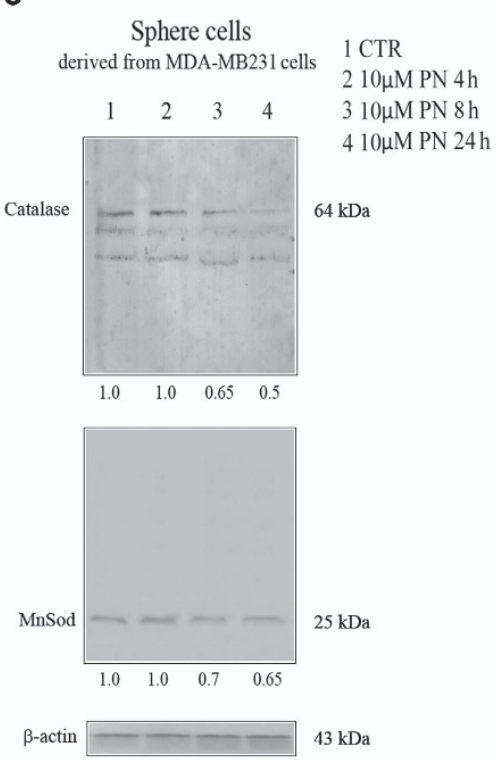

Sphere cells derived from MDA-MB231 cells
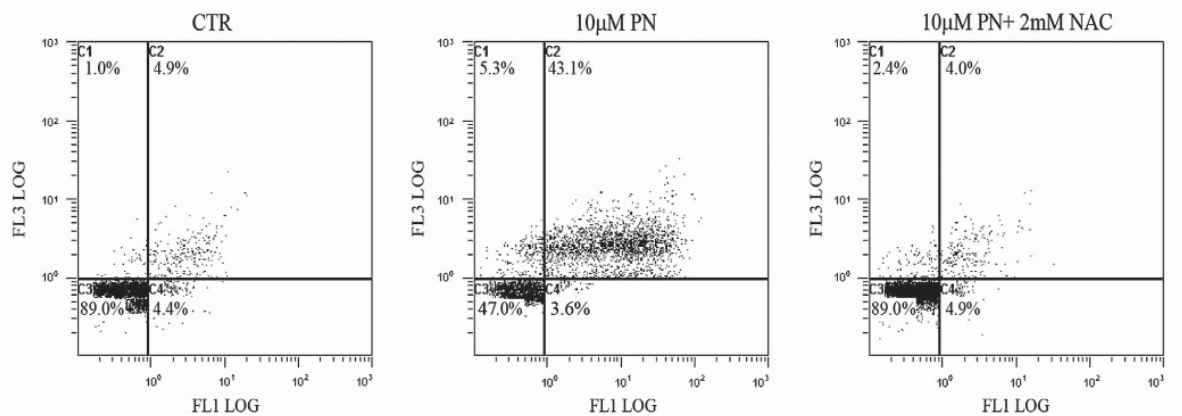

amino acids and $1 \mathrm{mM}$ pyruvate. Cells were grown in an incubator at $37^{\circ} \mathrm{C}$ in a humidified atmosphere containing $5 \% \mathrm{CO}_{2}$. Before each experiment, cells were seeded in 96- or 6-well plates and were allowed to adhere overnight, and then were treated with chemicals or vehicle only.

Mammosphere culture. Single cells of MDA-MB231, BT20 and MDA-MB436 lines were plated in ultralow attachment plates (Corning Incorporated Life Sciences,
Corning, NY, USA) at a density of 5000 viable cells per $\mathrm{ml}$ either in primary cultures or in the successive passages and grown in DMEM/Ham's F12 (Euroclone, Milan, Italy) without bovine pituitary extract, but supplemented with B27 (Life Technologies, Eugene, OR, USA), $20 \mathrm{ng} / \mathrm{ml}$ EGF, $20 \mathrm{ng} / \mathrm{ml}$ bFGF (Life Technologies) and $5 \mu \mathrm{g} / \mathrm{ml}$ Insulin (Sigma-Aldrich). Mammospheres were collected by gentle centrifugation after $10-12$ days and dissociated enzymatically with $0.05 \%$ trypsin, $0.02 \%$ EDTA (Sigma-Aldrich) and mechanically by a glass Pasteur pipette. Dissociated cells were 
Figure 6 PN caused mitochondrial depolarization and necrosis of sphere cells derived from three lines of TNBCs. (a and $\mathbf{b})$ Estimation of $\Delta \psi \mathrm{m}$. Sphere cells $\left(8 \times 10^{3}\right.$ cells per well) were treated for $24 \mathrm{~h}$ with $10 \mu \mathrm{M}$ PN without or with $2 \mathrm{mM}$ NAC. In condition IV, cells were treated with PN for only $4 \mathrm{~h}$, then the medium was substituted with fresh medium lacking in PN and the incubation was protracted until $24 \mathrm{~h}$. At the end of incubation in all samples, the fluorescent cationic dye JC-1 was added for 15 min and then fluorescence was visualized by a Leica microscope at x200 original magnification with fluorescent filters for FITC and rhodamine. Fluorescent sphere cells were counted in three different microscopic fields in each well ( 3 wells per treatment) and expressed as percentage of the total number of cells counted under light microscopy. (a) Merged images of an experiment performed using MDA-MB231 sphere cells. (b) Histograms showing the percentage of cells with green fluorescence ascertained for the three lines of sphere cells. (c) Western blotting analysis showing the effect induced by treatment for various times with $10 \mu \mathrm{M}$ PN on the expression of MnSOD and catalase in MDA-MB231 sphere cells. (d) Time course of the effect exerted by $10 \mu \mathrm{M}$ PN on the number of PI-positive cells. Sphere cells from the three lines of TNBCs were treated with $10 \mu \mathrm{M}$ PN for various times, then PI was added as reported in Materials and Methods and the percentages of PI-positive cells were ascertained. (e) Analysis by Annexin V/PI double-staining assay. After $24 \mathrm{~h}$

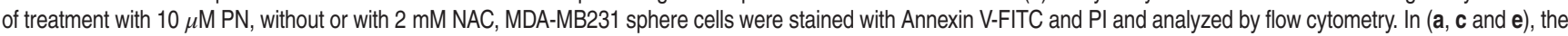
results are representative of three independent experiments. Scale bar, $10 \mu \mathrm{m}$. In $(\mathbf{b}$ and $\mathbf{d})$, the results are the mean of three independent experiments \pm S.D. ${ }^{*} P<0.01$ versus untreated control

passed through a 40- $\mu \mathrm{m}$ sieve and analyzed microscopically for single cells and used for the various experiments. Three passages were performed at intervals of 10-12 days.

Cell viability and cell death assays. Cell viability was ascertained, as described previously, ${ }^{14,15}$ by MTT method, a colorimetric assay. For these experiments, cells $\left(8 \times 10^{3} /\right.$ well) were plated in $200 \mu$ l of DMEM in a 96-well plate and treated for various times with PN or DMAPT or other compounds. Control samples were incubated for the established times in DMEM supplemented with vehicle only. At the end, the absorbance was measured directly at $490 \mathrm{~nm}$ in a 96well plate using an automatic ELISA plate reader (OPSYS MR; Dynex Technologies, Chantilly, VA, USA).

To determine extensive membrane damage, cells were treated, as suggested by Asare et al., ${ }^{55}$ with $\mathrm{Pl}$, a cell-impermeable nuclear dye, which stains the nuclei of cells that have lost plasma membrane integrity. After treatment of the cells $\left(8 \times 10^{3} /\right.$ well $)$ with PN or DMAPT, PI $(2.0 \mu \mathrm{g} / \mathrm{ml}$ medium $)$ was added and the incubation was protracted for additional $15 \mathrm{~min}$. At the end, cell morphology was visualized by a Leica MDR microscope equipped with a DC300F camera (Leica, Wetzlar, Germany) using rhodamine filter to examine PI with an excitation wavelength of 596 and emission wavelength of $620 \mathrm{~nm}$. Cells with red fluorescence were counted and normalized to total number of cells per field to calculate the percentage of PI-positive cells.

Apoptotic and necrotic effects were identified by using the Annexin V-FITC/PI Detection Kit (BD Biosciences, Pharmingen, San Diego, CA, USA) according to the manufacturer's instructions. Fluorescence of the cells was analyzed by flow cytometry on a Beckman Coulter Epics XL Flow Cytometer (Brea, CA, USA).

Analysis of $\Delta \psi \mathrm{m}$. The $\Delta \psi \mathrm{m}$ in CSCs was measured using the cationic dye $\mathrm{JC}$-1, which in depolarized mitochondria shows a fluorescence shift from red to green. Consequently, dissipation of $\Delta \psi \mathrm{m}$ was indicated by an increase in the green-to-red fluorescence-intensity ratio. After treatment with the drugs, cells $\left(8 \times 10^{3} /\right.$ well) were incubated with medium containing JC-1 (Cayman Chemical Company, Ann Arbor, MI, USA) for $15 \mathrm{~min}$ at $37^{\circ} \mathrm{C}$ and then washed two times with PBS. Then, the cells were analyzed on a Leica DMR fluorescence microscope (Leica Microsystems, Wetzlar, Germany) by using appropriate filters for rodhamine (excitation wavelength of $596 \mathrm{~nm}$ and emission wavelength of $620 \mathrm{~nm}$ ) and FITC (excitation wavelength of $485 \mathrm{~nm}$ and emission wavelength of $530 \mathrm{~nm}$ ).

Evaluation of ROS generation. To ascertain the effect exerted by both PN and DMAPT on ROS generation, we analyzed by fluorescence microscopy the changes produced by the two compounds on three different fluorescent signals: DCF, DHE and HPF.

$\mathrm{H}_{2}$-DCFDA (5-(and-6)-carboxy-2', $7^{\prime}$-dichlorodihydrofluorescein diacetate; Molecular Probe, Life Technologies, Eugene, OR, USA) is a cell-permeant, fluorogenic dye that easily diffuses across cell membranes. After cleavage of acetate groups by intracellular esterases, a fluorescent adduct (DCF) is produced by oxidation. This probe is widely used for $\mathrm{H}_{2} \mathrm{O}_{2}$. However, the probe lacks specificity as it also reacts with $\mathrm{hROS},{ }^{56}$ such as hydroxyl radical and peroxynitrite. Cells $\left(8 \times 10^{3} /\right.$ well) were treated with the effectors for various times. Then, the medium was removed, $100 \mu \mathrm{l}$ of $50 \mu \mathrm{M} \mathrm{H}_{2}$-DCFDA were added and the incubation was protracted for 30 min at $37^{\circ} \mathrm{C}$.

Production of superoxide anion was assessed by DHE (Sigma-Aldrich) staining. The fluorochrome DHE is oxidized by superoxide to fluorescent ethidium that intercalates with nuclear DNA, staining the nucleus with a bright red fluorescence. After treatment with PN, the cells were incubated with $20 \mu \mathrm{M}$ DHE in PBS for 15 min at $37^{\circ} \mathrm{C}$ in darkness.
HPF (Enzo Life Sciences Inc., Farmingdale, NY, USA) was used to detect hROS (hydroxyl radical and peroxynitite). HPF is a cell-permeable minimally fluorescent dye, which reacts with hROS, and is converted to fluorescein, which exhibits strong, dose-dependent fluorescence. ${ }^{56}$ For this analysis, cells, after the treatment, were incubated with $10 \mu \mathrm{M} \mathrm{HPF}$ in PBS for $1 \mathrm{~h}$ at $37^{\circ} \mathrm{C}$ in the dark.

In all the three cases at the end of incubation, the medium containing the fluorescent signal was replaced with PBS alone and the fluorescence was directly visualized by means of a fluorescence miscroscope.

All analyses were performed by a Leica DMR fluorescence microscope equipped with a DC300F camera with appropriate filters. FITC filter with excitation wavelength of $485 \mathrm{~nm}$ and emission wavelength of $530 \mathrm{~nm}$ was used for the analysis of DCF and HPF signals, while rhodamine filter with excitation wavelength of $596 \mathrm{~nm}$ and emission wavelength of $620 \mathrm{~nm}$ was used for DHE analysis. All the images were acquired by the Leica $Q$ Fluoro Software (Wetzlar, Germany). Cells with green or red fluorescence were counted and normalized to a total number of cells per field to calculate the percentage of cells producing ROS. Three fields per condition were analyzed.

Positivity of sphere cells to DCF signal was also evaluated by flow cytometer Epics $\mathrm{XL}$ (Brea, CA, USA). Cells ( $2 \times 10^{5} /$ well) were treated with the effectors for $1 \mathrm{~h}$. Then, the cells were harvested and incubated with $50 \mu \mathrm{M} \mathrm{H}_{2}$-DCFDA for 30 min at $37^{\circ} \mathrm{C}$ in darkness. After centrifugation (120xg for $5 \mathrm{~min}$ ), cells were resuspended in PBS and analyzed using flow cytometer with excitation and emission setting at 480 and $525 \mathrm{~nm}$, respectively.

RNA extraction and real-time PCR analysis. RNA was extracted by Trizol reagent (Life Technologies Ltd, Monza, Italy) and isolated using Direct-zol RNA MiniPrep Kit (Zymo Research, Irvine, CA, USA). Then, after removal of residual genomic DNA with DNase I (Zymo Research), oligo (dT)-primed reverse transcription was performed on $1 \mu \mathrm{g}$ of total cellular RNA using the iScript cDNA Synthesis Kit (Bio-Rad Laboratories Srl, Milan, Italy), following the manufacturer's instructions. For real-time PCR analyses, each CDNA sample was amplified by IQ SYBR Green Supermix (Bio-Rad Laboratories), as reported previously, ${ }^{57}$ using the QuantiTect primers Oct3/4, Sox2, Nanog ${ }^{58}$ (Qiagen, Milan, Italy). All PCR reactions were performed in triplicate in 96-well plates; each reaction mixture contained $2 \mu \mathrm{l}$ of template cDNA, $10 \mu \mathrm{l}$ of SYBR Green PCR Master Mix 2X (Bio-Rad Laboratories), forward and reverse primers at the concentration of $300 \mathrm{nM}$ and RNase-free $\mathrm{dH}_{2} \mathrm{O}$ to a final volume of $20 \mu \mathrm{l}$. Reactions were performed in $\mathrm{Q}$ 55 Thermal Cycler Instrument (Bio-Rad Laboratories), as reported previously. ${ }^{58}$ The relative quantities of analyzed genes were calculated using the $2^{-\Delta \Delta C t}$ method and the data were normalized with the endogenous control, GAPDH (Qiagen).

Western blotting analysis. Cell lysates and protein samples were prepared as reported previously. ${ }^{57}$ Equal amounts of protein samples ( $50 \mu \mathrm{g}$ per lane) were run in a SDS-polyacrylamide gel electrophoresis, and then transferred to a nitrocellulose membrane. All analyses were performed using specific primary antibodies, which were provided by Santa Cruz Biotechnology (Santa Cruz, CA, USA). Then, the detection was developed by using a secondary antibody conjugated with alkaline phosphatase. Protein bands were visualized using nitroblue tetrazolium and 5-bromo-4-chloro-3-indoyl-phosphate (Promega, Milan, Italy) and their intensity was quantified by densitometric analysis using the SMX Image software (Bio-Rad Laboratories). The correct protein loading was ascertained by red Ponceau staining and immunoblotting for $\beta$-actin. All the blots shown are representative of at least three different experiments. 
Statistical analysis. Results are presented as mean \pm S.D. of data from at least three independent experiments. Data were analyzed using Student's $t$-test. A $P$-value below 0.01 was considered significant.

\section{Conflict of Interest}

The authors declare no conflict of interest.

Acknowledgements. This work was partially funded by European Regional Development Fund, European Territorial Cooperation 2007-2013, CCI 2007 CB 163 PO 037, OP Italia-Malta 2007-2013. Drs. G Buttitta, R Di Fiore and R Drago-Ferrante benefit by contract grants supported by the same above-mentioned European Fund Italia-Malta 2007-2013. Dr. D Carlisi is a recipient of a grant by 'Italian Ministry of Education, University and Research' (MIUR).

1. Marles RJ, Pazos-Sano EL, Compadre CM, Pezzuto JM, Bloszyk E, Arnason J Sesquiterpene lactones revisited: recent developments in the assessment of biological activities and structure relationships. Rec Adv Phytochem 1995; 29: 333-356.

2. Knight DW. Feverfew: chemistry and biological activity. Nat Prod Rep 1995; 12: 271-276.

3. Pareek A, Suthar M, Rathore GS, Bansal V. Feverfew (Tanacetum parthenium): a systematic review. Farmacogn Rev 2011; 5: 103-110.

4. Zunino SJ, Ducore JM, Storms DH. Parthenolide induces significant apoptosis and production of reactive oxygen species in high-risk pre-B leukemia cells. Cancer Lett 2007; 254: 119-127.

5. Suvannasankha A, Crean CD, Shanmugam R, Faraq SS, Abonour R, Nakshatri $\mathrm{H}$ et al. Antimyeloma effects of a sesquiterpene lactone parthenolide. Clin Cancer Res 2008; 14: 1814-1822.

6. Hayashi S, Koshiba K, Hatashiba M, Sato T, Jujo Y, Shioura H et al. Thermosensitization and induction of apoptosis or cell-cycle arrest via the MAPK cascade by parthenolide, an NFkB inhibitor in human prostate cancer androgen-independent cell lines. Int J Mol Med 2011; 28: $1033-1042$.

7. Guzman ML, Rossi RM, Karnischky L, Li X, Peterson DR, Jordan CT et al. The sesquiterpene lactone parthenolide induces apoptosis of human acute myelogenous leukemia stem and progenitor cells. Blood 2005; 105: 4163-4169.

8. Kwok BH, Koh B, Ndubuisi MI, Elofsson M, Crews CM. The anti-inflammatory natural product parthenolide from the medicinal herb Feverfew directly binds to and inhibits IkB kinase. Chem Biol 2001; 8: 759-766.

9. Garcia-Pineres AJ, Lindenmeyer MT, Merfort I. Role of cysteine residues of p65/NF-KB on the inhibition by the sesquiterpene lactone parthenolide and $\mathrm{N}$-ethyl maleimide, and on its transactivating potential. Life Sci 2004; 75: 841-856.

10. Liu Z, Liu S, Xie Z, Pavlovicz RE, Wu J, Chan KK et al. Modulation of DNA Methylation by a sesquiterpene lactone parthenolide. J Pharmacol Exp Ther 2009; 329: 505-514.

11. Baker AM, Oberley LW, Cohen MB. Expression of antioxidant enzymes in human prostatic adenocarcinoma. Prostate 1997; 32: 229-233.

12. Sun Y, St Clair DK, Xu Y, Crooks PA, St Clair WH. A NADPH oxidase-dependent redox signalling pathway mediates the selective radiosensitization effect of parthenolide in prostate cancer cells. Cancer Res 2010; 70: 2880-2890.

13. Bauer KR, Brown M, Cress RD, Paradise CA, Caggiano V. Descriptive analysis of estrogen receptor (ER)-negative, progesterone receptor (PR)-negative and HER 2-negative invasive breast cancer, the so-called triple-negative phenotype: a population based study from the California Cancer Registry. Cancer 2007; 109: 1721-1728.

14. D'Anneo A, Carlisi D, Lauricella M, Di Fiore R, Vento R, Tesoriere G et al. Parthenolide generates reactive oxygen species and autophagy in MDA-MB231 cells. A soluble parthenolide analogue inhibits tumour growth and metastasis in a xenographt model of breast cancer. Cell Death Dis 2013; 4: e891.

15. Carlisi D, Lauricella M, Buttitta G, Di Fiore R, Rolfo C, Vento R, Tesoriere G et al. The synergistic effect of SAHA and parthenolide in MDA-MB231 breast cancer cells. J Cell Physiol 2014; 230: 1276-1289.

16. Bonnet $D$, Dick JE. Human acute myeloid leukemia is organized as a hierarchy that originates from a primitive hematopoietic cell. Nat Med 1997; 3: 730-737.

17. Reya T, Morrison SJ, Clarke MF, Weissman IL. Stem cells, cancer and cancer stem cells. Nature 2001; 414: 105-111.

18. Pardal R, Clarke MF, Morrison SJ. Applying the principles of stem-cell biology to cancer. Nat Rev Cancer 2003; 3: 895-902.

19. Al-Hajj M, Wicha MS, Benito-Hernandez A, Morrison SJ, Clarke MF. Prospective identification of tumorigenic breast cancer cells. Proc Natl Acad Sci USA 2003; 100: 3983-3988.

20. Donnenberg VS, Donnenberg AD. Multiple drug resistance in cancer revisited: the cancer stem cell hypothesis. J Clin Pharmacol 2005; 45: 872-877.

21. Costello RT, Mallet F, Gaugler B, Sainty D, Arnoulet C, Olive D et al. Human acute myeloid leukemia CD34+/CD38 - progenitor cells have decreased sensitivity to chemotherapy and Fas-induced apoptosis, reduced immunogenicity and impaired dendritic cells transformation capacities. Cancer Res 2000; 60: 4403-4411.
22. Graham SM, Jorgensen HG, Allan E, Pearson C, Alcorn MJ, Holyoache TL et al. Primitive, quiescent, Philadelphia-positive stem cells from patients with chronic myeloid leukemia are insensitive to ST1571 in vitro. Blood 2002; 99: 319-325.

23. Ponti D, Costa A, Zaffaroni N, Pratesi G, Petrangolini G, Daidone MG et al. Isolation and in vitro propagation of tumorigenic breast cancer with stem/progenitor cell properties. Cancer Res 2005; 65: 5506-5511.

24. Zhou J, Zhang H, Gu P, Bai J, Margolick JB, Zhang Y. NF-kB pathway inhibitors preferentially inhibit breast cancer stem-like cells. Breast Cancer Res Treat 2008; 111: 419-427.

25. Dontu G, Abdallah WM, Foley JM, Jackson KW, Clarke MF, Wicha MS et al. In vitro propagation and transcriptional profiling of human mammary stem/progenitor cells. Genes Dev 2003; 17: 1253-1270.

26. Kleniewska P, Piechota A, Skibska B, Goraca A. The NADPH oxidase family and its inhibitors. Arch Immunol Ther Exp 2012; 60: 277-294.

27. 't Hart BA, Copray S, Philippens I. Apocynin, a low molecular oral treatment for neurodegenerative disease. Biomed Res Int 2014; 2014: 298020.

28. Jagnandan D, Church JE, Banfi B, Stuehr DJ, Marrero MB, Fulton DJ. Novel mechanism of activation of NADPH oxidase 5. calcium sensitization via phosphorylation. J Biol Chem 2007; 282: 6494-6507.

29. Keum YS. Regulation of the Keap1/Nrf2 system by chemopreventive sulforaphane: implications of posttranslational modifications. Ann NY Acad Sci 2011; 1229: 184-189.

30. Tasset I, Pérez-De La Cruz V, Elinos-Calderón D, Carrillo-Mora P, González-Herrera IG, Santamaria A et al. Protective effect of tert-butylhydroquinone on the quinolinic-acid-induced toxicity in rat striatal slices: role of the Nrf2-antioxidant response element pathway. Neurosignals 2010; 18: 24-31.

31. Carlisi D, D'Anneo A, Emanuele S, Buttitta G, Tesoriere G, Lauricella M et al. The oxygen radicals involved in the toxicity induced by parthenolide in MDA-MB-231 cells. Oncol Rep 2014; 32: 167-172.

32. Motohashi H, Yamamoto M. Nrf2-Keap1 defines a physiologically important stress response mechanism. Trends Mol Med 2004; 10: 549-557.

33. Kensler TW, Wakabayashi N, Biswal S. Cell survival responses to environmental stresses via the Keap1-Nrf2-ARE pathway. Annu Rev Pharmacol Toxicol 2007; 47: 89-116.

34. Mackenzie IC. Stem cell properties and epithelial malignancies. Eur J Cancer 2006; 42: 1204-1212.

35. Diehn M, Clarke MF. Cancer stem cells and radiotherapy: new insights into tumor radioresistance. J Natl Cancer Inst 2006; 98: 1755-1757.

36. Vermeulen L, De Sousa E, Melo F, van der Heijden M, Cameron K, Medema JP et al. Wnt activity defines colon cancer stem cells and is regulated by the microenvironment. Nat Cell Biol 2010; 12: 468-476.

37. Grimes C, Margolin DA, Li L. Are cancer stem cells responsible for cancer recurrence? Cell Biol Res Ther 2012; 1 : 1.

38. Ghantous A, Sinjab A, Herceq Z, Darwiche N. Parthenolide: from plant shoots to cancer roots. Drug Discov Today 2013; 18: 894-905.

39. Wahba HA, El-Hadaad HA. Current approaches in treatment of triple-negative breast cancer. Cancer Biol Med 2015; 12: 106-116.

40. Dröge W. Free radicals in the physiological control of cell function. Physiol Rev 2002; 82 : 47-95.

41. Valko M, Leibfritz D, Moncol J, Cronin MT, Mazur M, Telser J. Free radicals and antioxidants in normal physiological functions and human disease. Int J Biochem Cell Biol 2007; 39: 44-84.

42. Diehn M, Cho RW, Lobo NA, Kalisky T, Dorie MJ, Clarke MF et al. Association of reactive oxygen species levels and radioresistance in cancer stem cells. Nature 2009; 458: 780-783.

43. Wu T, Harder BG, Wong PK, Lang JE, Zhang DD. Oxidative stress, mammospheres and Nrf2 - new implication for breast cancer therapy? Mol Carcinogen 2014; 54: 1494-1502.

44. Price LS, Langeslag M, ten Klooster JP, Hordijk PL, Jalink K, Collard JG. Calcium signaling regulates translocation and activation of Rac. J Biol Chem 2003; 278: 39413-39421.

45. Bánfi B, Tirone F, Durussel I, Knisz J, Moskwa P, Cox JA et al. Mechanism of $\mathrm{Ca}^{2+}$ activation of the NADPH oxidase 5 (NOX5). J Biol Chem 2004; 279: 18583-18591.

46. Itoh $\mathrm{K}$, Wakabayashi $\mathrm{N}$, Katoh $\mathrm{Y}$, Ishii $\mathrm{T}$, Igarashi $\mathrm{K}$, Yamamoto $\mathrm{M}$ et al. Keap1 represses nuclear activation of antioxidant responsive elements by Nrf2 through binding to the aminoterminal Neh2 domain. Genes Dev 1999; 13: 76-86.

47. Kobayashi A, Kang Ml, Okawa $\mathrm{H}$, Ohtsuji M, Zenke $\mathrm{Y}$, Yamamoto $\mathrm{M}$ et al. Oxidative stress sensor Keap1 functions as an adaptor for Cul3-based E3 ligase to regulate proteasomal degradation of Nrf2. Mol Cell Biol 2004; 24: 7130-7139.

48. Sun Z, Zhang S, Chan JY, Zhang DD. Keap1 controls postinduction repression of the Nrf2mediated antioxidant response by escorting nuclear export of Nrf2. Mol Cell Biol 2007; 27: 6334-6349.

49. Cullinan SB, Gordan JD, Jin J, Harper JW, Diehl JA. The Keap1-BTB protein is an adaptor that bridges Nrf2 to a Cul3-based E3 ligase: oxidative stress sensing by a Cul3-Keap1 ligase. Mol Cell Biol 2004; 24: 8477-8486.

50. Ren D, Villeneuve NF, Jiang T, Wu T, Lau A, Zhang DD et al. Brusatol enhances the efficacy of chemotherapy by inhibiting the Nrf2-mediated defense mechanism. Proc Natl Acad Sci USA 2011; 108: 1433-1438.

51. Olayanju A, Copple IM, Bryan HK, Edge GT, Sison RL, Park BK et al. Brusatol provokes a rapid and transient inhibition of Nrf2 signaling and sensitizes mammalian cells to chemical toxicity - implications for therapeutic targeting of Nrf2. Free Radic Biol Med 2015; 78: 202-212. 
52. Bayraktar S, Gluck S. Molecularly targeted therapies for metastatic triple-negative breast cancer. Breast Cancer Res Treat 2013; 138: 21-35.

53. Hudis CA, Gianni L. Triple-negative breast cancer: an unmet medical need. Oncologist2011; 1: $1-11$.

54. Xu Y, Fang F, Miriyala S, Crooks PA, Oberley TD, Clair WH et al. Keap1 is a redox sensitive target that arbitrates the opposing radiosensitive effects of parthenolide in normal an cancer cells. Cancer Res 2013; 73: 4406-4417.

55. Asare N, Lag M, Lagadic-Gossmann D, Rissel $M$, Schwarze $P$, Holme JA et al. 3-Nitrofluoroanthene (3-NF) but not 3-aminofluoroanthene (3-AF) elicits apoptosis as well as programmed necrosis in Hepa 1c1c7 cells. Toxicology 2009; 255: 140-150.

56. Setsukinai K, Urano Y, Kakinuma K, Majima HJ, Nagano T. Development of nove fluorescence probes that can reliably detect reactive oxygen species and distinguish specific species. J Biol Chem 2003; 278: 3170-3175.

57. Carlisi D, D'Anneo A, Lauricella M, Emanuele S, Vento R, Tesoriere G et al. Parthenolide sensitizes hepatocellular carcinoma cells to TRAIL by inducing the expression of death receptors through inhibition of STAT3 activation. J Cell Physiol 2011; 226: 1632-1641.
58. Di Fiore R, Marcatti M, Drago-Ferrante R, D'Anneo A, Tesoriere G, Vento R et al. Mutant p53 gain of function can be at the root of dedifferentiation of human osteosarcoma MG63 cells into 3AB-OS cancer stem cells. Bone 2014; 60: 198-212.

Cell Death and Disease is an open-access journal published by Nature Publishing Group. This work is licensed under a Creative Commons Attribution 4.0 International License. The images or other third party material in this article are included in the article's Creative Commons license, unless indicated otherwise in the credit line; if the material is not included under the Creative Commons license, users will need to obtain permission from the license holder to reproduce the material. To view a copy of this license, visit http://creativecommons.org/licenses/by/4.0/ 